\title{
Chamada para a inclusão da educação para a diversidade por meio das culturas-línguas no Ensino Fundamental I da escola pública
}

Éric Charles Brun ${ }^{1}$

\section{RESUMO}

Este artigo apresenta os conceitos básicos que sustentam uma educação para a diversidade no ensino Fundamental I no Brasil por meio da descoberta da diversidade das culturas-línguas como campo de saber transdisciplinar. As descobertas sonoras e visuais de várias culturas-línguas nacionais e não nacionais introduzem naturalmente a diversidade pela escuta de um outro ser diferente. A variedade das culturas-línguas se torna então um catalisador didático da diversidade global do mundo, compondo assim o eixo didático transdisciplinar que visa, coletivamente, à alteridade como supra objetivo educativo. Desta maneira, cada campo de saber escolar pode expressar a diversidade intrínseca da origem dos saberes humanos que o constituem. Nesta abordagem educativa, a alteridade, necessária para a paz social, ultrapassa as fronteiras nacionais para alcançar os outros locutores diferentes no mundo destacando, de forma precoce e simultânea, a identidade humana comum e a riqueza das diferenças. De forma concreta, o artigo sugere alguns conteúdos didáticos de uma abordagem da diversidade do $1^{\circ}$ ao $5^{\circ}$ ano do Ensino Fundamental elaborados de maneira a incluir gradativamente a complexidade do mundo (do próximo para o distante) e as interligações constantes com os outros saberes escolares (matemática, história, biologia, geografia, etc.). A mutação societal para um convívio mais harmonioso e equitativo passa por uma metamorfose da escola que vem a considerar a alteridade como aprendizagem humanista primordial, presidindo as abordagens dos outros componentes escolares. Esta mutação depende também de uma parceria estreita entre escola e família na qual se valorizaria a troca frequente de competências e experiências de cada sujeito.

Palavras-chave: Diversidade. Culturas. Línguas

1 Doutor em Ciências da linguagem (AMU, França). Professor adjunto do Departamento de Letras e Artes, Línguas Estrangeiras, Língua e literatura francesas da Universidade Estadual de Feira de Santana, BA. (UEFS). ORCID: http://orcid.org/0000-0002-5464-9468. E-mail: ecbrun@uefs.br. 


\section{Call for inclusion of education for diversity through cultures- language in elementary education of public school}

\section{ABSTRACT}

This article presents the basic concepts that support an education for diversity in Elementary Education in Brazil through the discovery of cultures-languages diversity as a transdisciplinary field of knowledge. The sound and visual discoveries of various national and non-national cultures-languages naturally introduce diversity through another different human being. The variety of cultures-languages then becomes a didactic catalyst of the world diversity, thus composing the transdisciplinary didactic axis that collectively aims at alterity as a supra educational goal. Therefore, each field of knowledge at school can express the intrinsic diversity of the origin of the human knowledge that constitutes it. In this educational approach, alterity, which is necessary for social peace, goes beyond national boundaries to reach the other different speakers in the world, highlighting, at an early stage, the common human identity and the richness of differences. Specifically, the article suggests didactic contents of an approach of diversity from 1st to 5th year of Elementary School, elaborated in a way that gradually includes the complexity of the world (from a near to distant perspective) and the constant interconnections with the other school knowledge (Mathematics, History, Biology, Geography, etc.). The societal transformation to a more harmonious and equitable conviviality depends on a metamorphosis of the school that begins to consider alterity as primordial humanistic learning, presiding over the approaches of other school subjects. This mutation also depends on a close partnership between school and family in which the frequent exchange of skills and experiences of each subject is valued.

Keywords: Diversity. Cultures. Languages.

\section{Llamada para la inclusión de la educación a la diversidad a través de las culturas-lenguas en la Escuela Primaria}

\section{RESUMEN}

Ese artículo presenta a los conceptos básicos que apoyan une educación para la diversidad en la Escuela Primaria en Brasil a través 
del descubrimiento de la diversidad de las culturas-lenguas como área de conocimiento transdisciplinaria. Las descubiertas sonoras y visuales de varias culturas-lenguas nacionales y no nacionales introducen naturalmente a la diversidad a través de otro ser diferente. La variedad de las culturas-lenguas se vuelve por lo tanto en catalizador didáctico de la diversidad global del mondo así componiendo el eje didáctico transdisciplanario que suele lograr colectivamente a la alteridad como supra meta educativa. De este modo, cada área de conocimiento académico puede expresar la diversidad intrínseca del origen des les conocimientos humanos que la constituyen. Con ese enfoque académico, la alteridad, necesaria para la paz social, excede las fronteras nacionales para alcanzar a otros interlocutores diferentes del mondo subrayando, de modo precoz y simultaneo, la identidad humana común y la riqueza de las diferencias. De forma concreta, el articulo sugiere algunos contenidos didácticos de un planteamiento de la diversidad del $1^{\circ}$ hasta el $5^{\circ}$ año de la Escuela Primaria elaborado de modo a incluir gradualmente la complejidad del mondo (de su alrededor hasta más lejos) y las interconexiones constantes con los otros conocimientos académicos (matemáticas, historia, biología, geografía, etc.). La conversión societal hacia una convivencia más harmoniosa y ecuánime sucede a una metamorfosis de la escuela que empieza a considerar a la alteridad como enseñanza humanista primordial presidiendo los enfoques de los otros componentes académicos. Esa mutación depende también de una asociación estrecha entre escuela y familia en la cual se valora el intercambio frecuente de competencias y experiencias de cada sujeto.

Palabras clave: Diversidad. Culturas. Lenguas.

\section{Introdução}

A orientação didática de cultura-língua não nacional, seja no Brasil, seja em outro país, transparece inevitavelmente através do conceito semântico que a instituição lhe atribui e que o corpo docente e a(o) s pesquisadora(e)s retomam.

A primeira orientação implícita, no caso do Brasil, provém do conceito perene de língua estrangeira moderna (BRASIL, 1998) segundo o qual a língua apresenta-se desligada da cultura, ou seja, do seu locutor, aquele outro diferente. Esta ausência semântica neste conceito 
tem por corolário, consciente ou inconsciente, a instauração tenaz de uma abordagem didática principalmente linguística, ou seja, estrutural.

A segunda orientação implícita deste conceito é que ele continua mantendo uma característica excludente deste outro diferente através da sua estraneidade que remete à distância irreversível entre o aprendiz e um locutor nativo, omitindo assim que: "uma língua não é 'estrangeira' em si: este adjetivo testemunha de um posicionamento por parte de um indivíduo ou de um grupo de indivíduos" (CHINI; GOUTÉRAUX, 2011, p. 136, nossa tradução). Esta orientação tácita é encontrada na expressão foreign language em inglês, mas desaparece no conceito francês de langue vivante (língua viva). Este implícito semântico enclausura irremediavelmente o outro locutor na sua diferença e gera uma dinâmica discriminante consciente ou inconsciente.

Além destas duas orientações implícitas próprias ao sistema educativo brasileiro, os sistemas educativos ocidentais compartilham uma abordagem singular do ensino-aprendizagem de outra cultura-língua (CANDELIER, 2012), isto é, a escolha de uma única língua (geralmente hegemônica) e de introdução tardia no Brasil (ensinada a partir do $6^{\circ}$ ano no Brasil e geralmente a partir do $1^{\circ}$ ano na Europa). Mesmo quando uma segunda outra cultura-língua é oferecida num sistema educativo ocidental, ela é oferecida consecutivamente a outra nos primeiros anos. $\mathrm{Na}$ França, por exemplo, as duas línguas vivas passam a ser ensinadas simultaneamente a partir do $6^{\circ}$ ano.

Esta abordagem singular se apoia erroneamente na crença de que uma língua é apenas uma ferramenta que precisa de tempo (duração de aprendizagem) para ser construída (competências) (BRUN BRUN, 2016). Assim, a outra cultura-língua na escola não parece ter um papel educativo global (como as matemáticas, a biologia, o português etc.), mas parece ser um meio pragmático de conseguir a curto prazo falar inglês ou espanhol para conquistar mercados. Esta prática é recorrente na Europa e crescente na França, onde 91,7\% das escolas públicas optam pelo inglês (FRANÇA, 2017, p. 72).

A primeira parte deste artigo define os conceitos básicos de uma educação para a diversidade no ensino Fundamental I no Brasil, enquanto a segunda parte apresenta as estruturas didáticas desta abordagem da diversidade através, principalmente, das culturas-línguas como eixo transdisciplinar comum. 


\section{A diversidade das culturas-línguas como processo educativo transdisciplinar autoconstituinte}

O frágil estatuto educativo das línguas estrangeiras modernas no Brasil não parece corresponder à pluralidade cultural-linguística histórica desta nação. Esta pluralidade fecunda entre várias etnias endêmicas (povos indígenas) e não endêmicas (povos invasores) procede de um processo de miscigenação violento como em quaisquer outros processos constitutivos nacionais no planeta. A política básica da formação dos Estados-Nações é a homogeneização da diversidade espalhada no território. Assim, a diversidade é para Philippe Blanchet (BLANCHET, 2016, p. 55, nossa tradução): "percebida de maneira negativa, ainda mais em certas épocas não tão distantes onde a diversidade em geral era quase nunca percebida como uma riqueza para proteger, mas pelo contrário, como um obstáculo nefasto a ser derrubado". Embora a diversidade apareça cada vez mais como uma riqueza cognitiva humana, ela permanece ainda como uma visão intelectual idealizada do mundo.

Para Edgar Morin (MORIN, 2009, p. 25, nossa tradução), que aponta o efeito avassalador da homogeneização forçada da diversidade, o século XX inventou: "a monstruosidade de nação mono-étnica". Assim, os Estados-Nações passaram a incluir nas suas respectivas constituições, de forma às vezes tardia, uma única língua oficial ainda que sejam constituídos por uma grande variedade de culturas-línguas regionais. É o caso da França, que incluiu a língua francesa como língua da República apenas em 1992. Como assinala o sociolinguista Philippe Blanchet:"muitas vezes, como na França, erigiram a língua (uma língua só sob uma única variedade normativa) em totem sagrado de comunicação patriótica" (BLANCHET, 2011, p. 290-291, nossa tradução).

Desta forma, nesta lógica comum, as exceções se destacam com mais força, como por exemplo nos Estados-Unidos onde, a fim de respeitar a sua constituição historicamente plural, não foi definida nenhuma língua oficial federal (na realidade, apenas 29 estados adotaram o inglês como única língua oficial), na Nova-Zelândia (cultura-língua maori) e na África do Sul (três culturas-línguas africanas e duas de origem europeia) que alteraram os seus respectivos hinos nacionais para incluir trechos em línguas autóctones. 
A abordagem intercultural desde os anos 1990 foi concebida em didáticas de culturas-línguas para reequilibrar as tendências das abordagens estruturais (foco principalmente linguístico) que torna o aprendizado simbolicamente desumanizante onde a língua aparece como independente de um locutor. A língua apresenta-se então como algo que poderia ser utilizado por qualquer usuário, em qualquer situação de uso e com qualquer atitude em relação ao outro diferente. Este princípio educativo é por definição paradoxal em didáticas de culturas-línguas, já que ele se constrói a partir da homogeneidade não apenas dos aprendizes, mas também dos grupos humanos visados pela aprendizagem, como no caso de um inglês básico comum à centena de nações que o escolheu como língua oficial. Neste caso específico do inglês, a didática de cultura-língua se torna uma didática de língua (oral e escrita) que neutraliza as variedades culturais peculiares dos seus locutores. Muitas vezes, esta escolha pode aparecer como um dilema para o educador que deve optar entre a referência histórica britânica ou a referência moderna e tecnológica estadunidense. Afinal, apresentar outra língua sem a diversidade cultural dos seus locutores inseridos nos seus respectivos espaços geográficos procede de uma lógica hegemônica que valoriza mais a mensagem do que o locutor.

Quando falamos de diversidade na escola, pensamos frequentemente em inclusão de um outro diferente ou de algo diferente sempre em relação a nosso próprio, peculiar e individual sistema de referência seja a nação, a região, o estado, o município, a escola, o grupo da sala de aula ou a família, nossos ancestrais comuns ou nossos fenótipos semelhantes dominantes. Hoje em dia, nesta era digital, esta dinâmica etnocêntrica não pode mais estar ligada à carência informativa. $\mathrm{O}$ aprendiz pode observar instantaneamente o que é semelhante no outro e o que é diferente sem passar pela legitimidade docente. Aliás, o aluno costuma conferir às vezes na sala de aula as afirmações do corpo docente a partir da sua conexão à internet. A dinâmica etnocêntrica persistente é inerente às atitudes e aos comportamentos comuns desenvolvidos e fortalecidos dentro do próprio grupo ao qual nós nos identificamos.

O paradoxo do processo educativo escolar surge quando se trata de considerar um grupo humano como homogêneo numa lógica simplificadora. Ao ignorar e não salientar a heterogeneidade humana, 
qualquer didática fortalece inevitavelmente a dicotomia entre o normal e o anormal, por meio de normas comuns, de regulamentos internos, de atitudes e comportamentos normalizados dentro do grupo e das suas próprias regras de comunicação. Se as normas na sociedade podem ser contempladas como princípios cívicos de convívio social, elas são também e paradoxalmente em várias situações culturais-linguísticas "as relações de poder e de domínio que instauram as discriminações" (BLANCHET, 2016, p. 40, nossa tradução).

Na lógica cívica, o processo educativo se torna então integrativo, na medida em que o seu objetivo principal visa à integração a um macro sistema (escola) da heterogeneidade das crianças oriundas de contextos diversos (famílias). O processo integrativo emana de um sistema educativo que é preexistente à chegada da criança na escola. Ele não procede de uma renegociação com as crianças nem com as suas famílias, o que torna esta integração ou inclusão imposta por um sistema dominante.

Para Peter Berger e Thomas Luckmann (BERGER; LUCKMANN, 2010, p. 129-130, nossa tradução): "A prioridade das definições institucionais das situações deve ser constantemente mantida de modo a reprimir toda tentativa de redefinição. As crianças devem "aprender a se comportar", e uma vez isto feito, elas devem aprender a "ficar na fila". Este processo de inclusão passa por três fases características: 1) a identificação da diferença (deficiência, origem nacional ou regional, estatuto econômico-social, fenótipo, idade, religião, etc.); 2) o reconhecimento coletivo desta identificação (etapa frequentemente traumatizante pela rotulação da diferença sempre aproximativa e excludente); 3) o convívio tolerante com este outro diferente que se transforma num processo magnânimo de um dominante para outro dominado e que, afinal, não contribui: "Para a edificação de uma sociedade mais justa, mais igualitária, mais interligada entre umas(uns) e outra(o)s e visando, não a tolerância das diferenças, mas a hospitalidade em relação à alteridade" (CLERC, 2011, p. 176, nossa tradução). O sistema de cota no ensino superior no Brasil ou de discriminação positiva na França tem como objetivo lutar contra a desigualdade econômica e social para reverter paradoxalmente as consequências geradas pelo próprio sistema societal. Assim, a discriminação positiva visa, segundo Baptiste Villenave (2006, p. 39, nossa tradução): 
Instituir desigualdades para promover a igualdade concedendo para alguns um tratamento preferencial. Espera-se desta forma restabelecer uma igualdade das chances prejudicadas por dois fenômenos: a generalização ou a persistência das práticas racistas ou sexistas de um lado, uma acentuação das desigualdades socioeconômicas do outro lado.

A tendência de resolução de uma política educativa é comumente tratar os sintomas (as discriminações observadas) a partir de promulgação de regras de convívio harmonioso ao nível microsocial (a escola) ou de resoluções e leis ao nível macrossocial (estado ou federação). Porém, estes sintomas são apenas elementos periféricos do núcleo do preconceito, isto é, aqueles comportamentos mais visíveis. O núcleo do preconceito é atitudinal, ou seja, é da ordem do pensamento individual com espelhamento frequente numa atitude coletiva. A psicologia social já mostrou o quanto a alteração do núcleo de uma representação social acerca de um outro diferente é lenta e infinitésima (ABRIC, 1994; PEREIRA DE SÁ, 1996). Se as formas e a intensidade da discriminação variam entre os grupos humanos, a tendência natural a discriminar é uma constante. A criança do Ensino Fundamental I está construindo a sua primeira socialização real através da sua experiência escolar e da transferência emocional com a(o) docente que se torna fundamental:

\begin{abstract}
A socialização primária envolve mais do que uma simples aprendizagem cognitiva. Ela se instala dentro de circunstancias que são fortemente carregadas emocionalmente. De fato, é bastante provável que sem este apego emocional com outros significativos, o processo de aprendizagem seria difícil a realizar senão impossível. A criança se identifica com os outros significativos de diversas maneiras emocionais (BERGER; LUCKMANN, 2010, p. 226-227)
\end{abstract}

Todavia, o impacto educativo familiar nos primeiros anos da escolaridade da criança é preponderante e a escola, dificilmente, conseguirá reverter as representações construídas dentro da família. Assim, a atitude que sustenta o preconceito vem da emoção e precede, portanto, a socialização primária, ou seja, o convívio escolar (PREISSING; WAGNER, 2006). O preconceito já faz parte da construção cognitiva da criança desde a Educação Infantil e apenas um projeto pedagógico a longo prazo, 
incluindo uma formação docente adequada e uma reanálise das abordagens pedagógicas-didáticas seria capaz de superar as representações familiares.

Contudo, dispor de um projeto pedagógico antidiscriminante não garante para a instituição escolar uma educação alteritária, na medida em que ele depende também, e sobretudo, das atitudes do seu corpo docente em relação à diversidade. Por mais que esta meta alteritária pareça ser condição sine qua non de qualquer sistema educativo que busca o descobrimento do altruísmo (como concebido por Auguste Comte em 1852), nem sempre o seu corpo docente está em sinergia com as diretrizes escolares.

Por outro lado, as aprendizagens escolares continuam sendo elaboradas a partir das disciplinas ditas de referências, como a matemática e a língua oficial às custas dos conteúdos sociais e humanistas que visariam primeiramente o convívio social com os outros diferentes. $O$ altruísmo considera que todas as medidas educativas e sociais só podem ter como único objeto o seu prevalecimento sobre o egoísmo humano (DIXON, 2012, p. 304). Para Edgar Morin (MORIN, 2004, p.17, tradução nossa): "Cada um vive para si e para outro de maneira dialógica, isto é, no mesmo tempo de maneira complementária antagônica. Ser sujeito é conjuntar o egoísmo e o altruísmo". Um dos papeis da escola, por estar ao serviço da comunidade, é a construção do altruísmo para tentar frustrar o egoísmo inato. Esta construção é a aprendizagem do civismo por meio da internalização profunda e verdadeira das regras societais, ou seja, incorporando estas regras nas atitudes para adequar o comportamento de forma perene e ética a longo prazo e não apenas quando a regra satisfaz o próprio interesse pessoal e individual. A paz social é interligada com a alteridade que aspira a se tornar, portanto, um princípio fundador de qualquer grupo humano que naturalmente não está disposto a fraternizar com outro grupo humano. É a soma de todos os egoísmos individuais dentro de um coletivo que nos leva ao etnocentrismo:

As éticas comunitárias são universais no sentido que todas as sociedades, dos clãs às nações, prescrevem a solidariedade e a responsabilidade dentro da comunidade. Mas, elas são peculiares no sentido que as suas prescrições perdem totalmente validade fora 
das suas comunidades. (MORIN, 2004, p. 190, nossa tradução)

A escola precisa destacar para as crianças o mais cedo possível a nossa identidade bio-antropológica comum (MORIN, 1993, p.65, nossa tradução) dentro da diversidade humana. Em caso de ausência ou fragilidade dos princípios alteritários, a tendência etnocêntrica humana leva o indivíduo ao fortalecimento dos subgrupos sob a forma de micro- organizações sociais que, por não se identificarem com a macro organização nacional, ou se proteger dela (reservas indígenas, escolas particulares, escolas públicas, comunidades quilombolas, igrejas etc.), se isolam, transformando assim a diversidade num patchwork sócio-cultural-linguístico em vez de um mosaico enriquecedor. Esta identidade bio-antropológica comum faz parte de um ideal humanista antigo, por meio do cosmopolitismo e deu forma ao cosmopolitismo abstrato que: "promove o apagamento das fronteiras: a humanidade é uma, todos os homens são cidadãos do mesmo mundo e este mundo ignora a divisão entre autóctones e estrangeiros" (LAMARRE, 2012, p. 4, nossa tradução).

Na mesma linha sociofilosófica, Edgar Morin que deplora que: "no encontro das culturas, a incompreensão prevalece ainda em relação à compreensão" (MORIN, 1993, p. 42, nossa tradução), propõe o conceito de cidadania terrestre $(1982,1993)$. Assim, cada Estado-Nação vislumbra, analisa e administra a simbiose humana com outro diferente de forma peculiar (leis nacionais e práticas sociais variáveis, como é o caso da variabilidade legal entre Federação e Estados no caso do Brasil e dos Estados-Unidos e entre a lei nacional e os decretos municipais na Europa), e simultaneamente de forma universal(leis internacionais e práticas universais invariáveis, representadas por um leque de organismos internacionais: Cruz Vermelha (1863), Convenção de Genebra (1864), ONU e UNESCO (1945), UNICEF (1946), OMS (1948), entre outros). A proeza da humanidade então é o projeto cada vez mais articulado de criação de uma cidadania planetária, mesmo que esta seja contrária ao instinto do Homo Economicus aquele que, segundo Morin (2009) "se determina em função do próprio interesse". De fato, esta proeza parece estar acontecendo quase exclusivamente por meio da troca de bens e a partir do interesse econômico. A micro sociabilidade humana (interesse circunscrito ao vizinho ou ao elemento próximo) se torna cada vez mais ultrapassada 
pelas tecnologias de comunicação e pela circulação síncrona das informações.

No entanto, esta dinâmica foi iniciada antes da era da Internet e desta globalização moderna, como o confirma Jean-Jacques Rousseau (ROUSSEAU, 1755-1894, p. 159, nossa tradução) quando ele observa que: "hoje que o comércio, as viagens e as conquistas reúnem mais os povos diversos e que seus modos de viver se aproximam sempre mais pela frequente comunicação, percebe-se que algumas diferenças nacionais diminuíram". O único parâmetro realmente recente é a invenção de um sistema de educação nacional em cada Estado-Nação que vai federar os indivíduos dispersos com suas naturezas egoístas. O senso cívico (voltado para o grupo inteiro) vai então nascer da escola assim como o senso crítico que é a capacidade de descentramento do indivíduo do seu grupo de pertencimento. Mas este senso crítico em si não é suficiente para lutar contra os preconceitos e as discriminações oriundos de um longo histórico atávico fortalecido na escola a partir de referências coletivas comuns (cantigas, contos e jogos nacionais, cujas origens não são tão nacionais...). A introdução de novas referências literárias, científicas ou lúdicas na escola fundamental estimula a alteridade das crianças e a sua curiosidade justamente por serem referências desconhecidas. Os sistemas educativos nacionais se construíram e se modificaram a partir da forma peculiar interna (nacional) dominada totalmente pelo Homo Economicus que, para alcançar a plenitude econômica, precisou imaginar a homogeneidade nacional, isto é, domando ou destruindo as tentativas separatistas que a maioria das nações do planeta já enfrentou.

Estas tentativas (normalmente impedidas pela lógica federativa) são a expressão de uma diversidade frustrada quando uma minoridade étnica-cultural-linguística-religiosa exige o seu afastamento de uma maioridade que não a representa. Nossa capacidade simbiótica com o outro diferente é proporcional à distância que nos separa dele. Somos tribais e clânicos. Portanto, a aparente metamorfose societal rumo a mais alteridade não procede do sistema educativo que é, por definição, autárquico em razão do seu fechamento etnocêntrico, mas procede das trocas essencialmente econômicas com o mundo afora.

Efetivamente, são estas trocas que, gerando outras referências culturais-linguísticas, outros modos de pensar e interagir, de contar, de olhar para o outro ou não, de fazer mímicas ou gestos etc., vão introduzir 
nos hábitos os elementos desviantes necessários para alterar as atitudes e comportamentos de um grupo etnocêntrico a partir da desordem "mais rica ainda do que a ideia de ordem já que ela comporta necessariamente um polo objetivo e um polo subjetivo" (MORIN, 1982, p.185) ou da anormalidade já que "a personalidade de base é uma norma porque ela representa o que o conjunto dos membros de um grupo considera como normal" (VINSONNEAU, 2000, p.115). Contudo, qualquer organização humana mudará a partir deste confronto com um desvio que precisa se transformar em tendência (MORIN, 1991). É um processo educativo a longo prazo.

Se o papel dos sistemas educativos nacionais do mundo acerca da construção de atitudes positivas com a diversidade está cada vez mais nítido e internalizado, os resultados societais concretos nem sempre parecem à altura das nossas expectativas em relação à recorrência dos conflitos civis ou internacionais. Se muitos conflitos são basicamente binários, seja de cunho econômico seja religioso, eles têm uma base comum que é em regra geral o preconceito. De fato, para um conflito nascer, é necessário que um indivíduo dominante (ou o seu grupo de pertencimento) identifique um outro diferente potencialmente dominável. O dominante justifica usualmente a passagem ao ato, seja por atos de separação real e/ou simbólicos (conflito Israelo-Palestino, muro de Berlim, reservas indígenas, estrela de Davi amarela antissemita, castas indianas, sexismo, etc.) a partir de uma interpretação da história da humanidade composta inevitavelmente de conflitos entre grupos dominantes e grupos dominados.

O processo de mutação da humanidade passa pela internalização da alteridade e não apenas pela tolerância que é somente uma etapa necessária. Nossos grupos humanos caracterizados pela sociabilidade (embora seja mais precisamente uma sociabilidade de proximidade) carecem ainda de descobrir a auto constituição alteritária, ou seja, um processo cognitivo baseado na empatia com o outro diferente e não no seu interesse particular. Este processo exige, num primeiro tempo, a neutralização de nossa visão do mundo normalizada pela história da humanidade que nos leva a reproduzir numa dinâmica cultural recursiva (sistema fechado) atitudes e comportamentos herdados (observáveis através das expressões idiomáticas de tendências discriminantes, os sistemas representacionais acerca da diversidade, os estereotípicos comuns do grupo, etc.). A segunda etapa visa à aprendizagem de descentramento cultural, que só se torna 
possível a partir do questionamento das normas herdadas e que podem ser totalmente desatualizadas. E a última e terceira fase estabelece as novas normas alteritárias comuns ao grupo. Afinal, a alteridade não é inata. É uma aprendizagem imprescindível, que deve consequentemente tornar-se uma aprendizagem escolar coletiva preponderante.

\section{A diversidade das culturas-línguas da educação infantil ao $5^{\circ}$ ano do ensino fundamental}

A abordagem singular de uma outra cultura-língua na escola é profundamente antagônica à diversidade da humanidade. Para se introduzir uma educação para a diversidade é necessário pelo menos reconhecê-la por meio de um projeto perene que abarcaria todos os campos de saber. $\mathrm{O}$ tronco comum deste projeto transdisciplinar seria constituído pelas línguas e linguagens, por meio das quais a criança pudesse se expressar seja oralmente, seja por sinais, por equações matemáticas ou químicas, pela arte ou pela mímica. É a transdisciplinaridade que introduz naturalmente a diversidade reunindo os diversos campos de saber.

A aprendizagem da alteridade é posterior ao descobrimento da diversidade. É um descobrimento, já que esta diversidade faz parte do dia a dia de qualquer criança do mundo a partir das próprias observações realizadas dentro da família ou no bairro onde ela mora. Trata-se de recorrer às observações empíricas que a criança constrói em família ou na escola de forma contínua ao nível individual para apresentá-las e desenvolvê-las de forma coletiva dentro da sala de aula.

A alteridade será alcançada quando a diversidade se tornar a nova norma instituindo todas as possibilidades trazidas pela pluralidade de visões do mundo, de sons, de visuais, de tamanhos, de aparências, de cor de cabelo, cor de pele, de olhos, de forma etc. Sem o processo prévio de desconstrução normativa da escola, o elemento diferente introduzido será sempre considerado como diferente e não como diverso. A diversidade permeia naturalmente qualquer campo de saber escolar, além de ser uma aprendizagem social ampliada à escola inteira e às famílias e não apenas ao grupo da sala de aula. A sua natureza profunda é transdisciplinar. Portanto, é preciso construir um projeto pedagógico-didático a partir da educação para a diversidade como eixo central da Educação Infantil ao $5^{\circ}$ ano, transformando os outros campos de saber (disciplinas) em ramificações secundárias. As 
atividades desenvolvidas neste eixo central objetivariam três categorias principais:

1) Apresentar para a criança de forma lúdica a partir de um suporte didático audiovisual universal (filmes infantis, contos, músicas e artes) a realidade quantitativa da diversidade linguística do mundo e simultaneamente a semelhança de uma temática comum com as crianças do mundo;

2) Estimular a criança a partir de um suporte audiovisual em outra língua sonora ou/e escrita para se esforçar a compreender (empatia) a mais ampla variedade possível de sons ou de grafias diferentes e observar as semelhanças;

3) Mostrar para a criança a mais ampla diversidade visual real humana possível (fenótipos, e vestuários) a partir de suportes audiovisuais autênticos (evitando desenhos pouco realistas e frequentemente caricaturais do outro diferente) de maneira a desconstruir os estereótipos e preconceitos em formação através da valorização das semelhanças.

A escola precisa apenas elaborar um projeto pedagógico comum, ou seja, envolvendo todos os níveis escolares para definir a longo prazo os conteúdos e as abordagens didáticas para cada ramificação (figuras 1 a 4). A transdisciplinaridade tomaria a forma de um rizoma para juntar os campos de saber, aproximar as ciências exatas das ciências humanas e sociais e criar conexões entre os saberes.

\section{Progressão didática dentro de uma educação para a diversidade por meio das culturas-línguas}

Da Educação Infantil até o $1^{\circ}$ ano do Fundamental, a abordagem da diversidade do mundo precisa ser genérica, próxima e sensitiva. O genérico oferece a possibilidade de atravessar os campos de saber, valorizando mais a dinâmica do que o próprio conteúdo. Esta dinâmica é fundamental para a criança aprender a construir e a desconstruir simultaneamente as suas certezas ao ritmo das descobertas, alternando continuamente suas normas. A proximidade visa ativar os saberes da criança a partir do mundo que a cerca e que ela já conhece, assim como descobrir que a diferença já faz parte do seu dia a dia. A figura seguinte esquematiza esta didática da diversidade para os dois primeiros anos: 
Figura 1- Da Educação Infantil ao $1^{\circ}$ ano do Ensino Fundamental

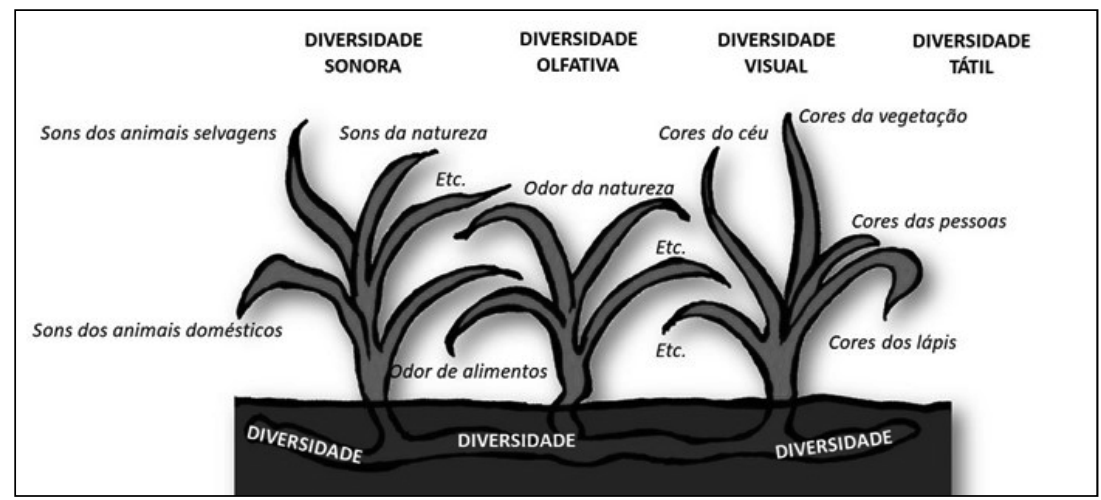

Fonte: Elaborada pelo autor

A abordagem da diversidade se torna em seguida cada vez mais específica a partir do $1^{\circ}$ ano, acompanhando os programas escolares, mas incluindo conexões com a diversidade cultural-linguística próxima,

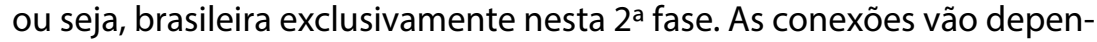
der do contexto social, econômico, cultural e linguístico da região escolar para incluir a realidade quotidiana da criança (comunidades indígenas, comunidades quilombolas, diversidade das moradias etc.) e não uma diversidade distante e desconhecida:

Figura 2 - Do $1^{\circ}$ ao $2^{\circ}$ ano

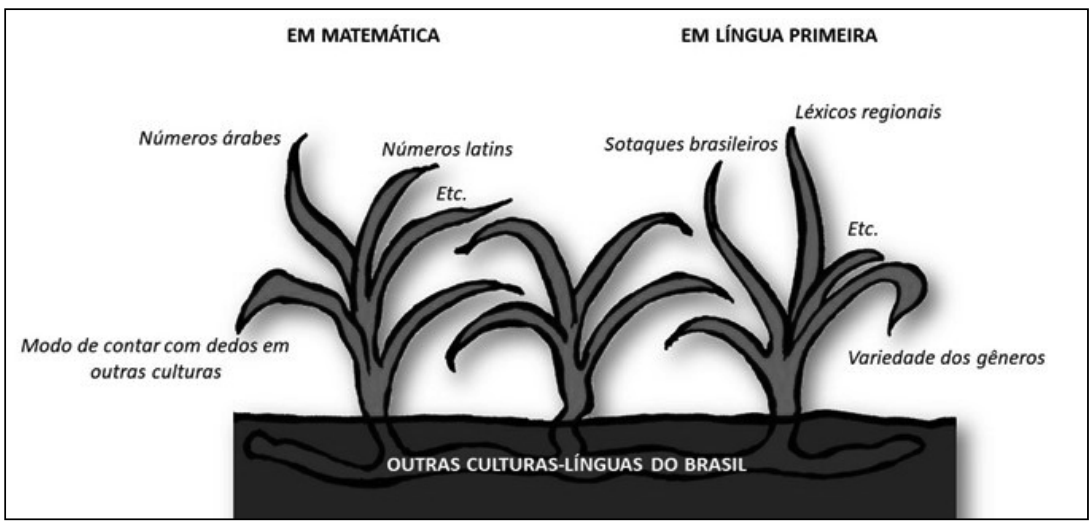

Fonte: Elaborada pelo autor

Nos $2^{\circ}$ e $3^{\circ}$ anos, os conteúdos das ramificações se tornam mais específicos e complexos, acompanhando sempre desta forma os con- 
teúdos programáticos escolares, mas ampliando a zona geográfica dos campos de saber para além das fronteiras brasileiras a fim de abarcar o continente sul americano todo:

Figura $3-2^{\circ}$ e $3^{\circ}$ anos

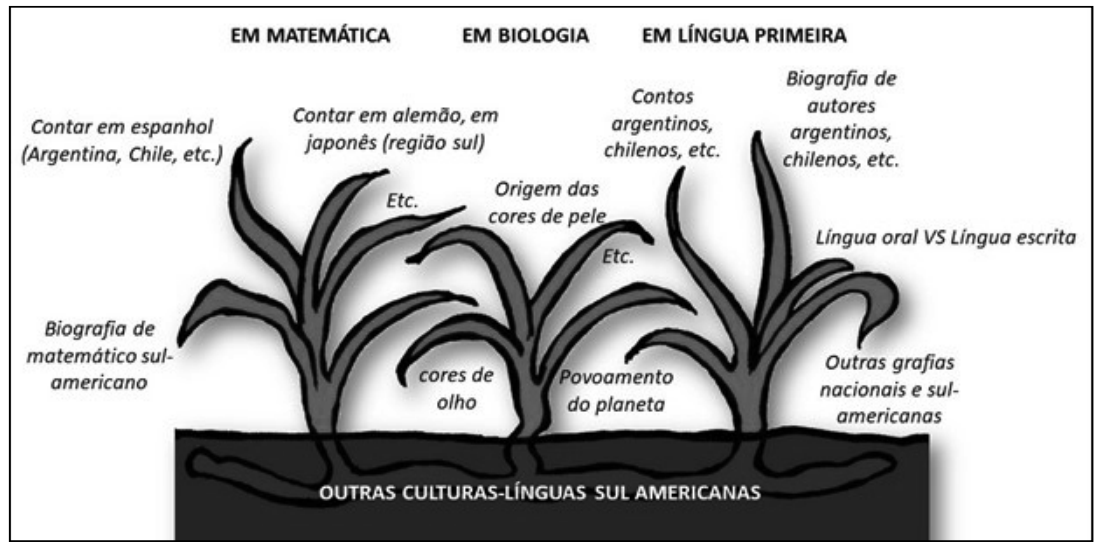

Fonte: Elaborada pelo autor

E, por fim, as ramificações alcançam uma zona geográfica sem limite, criando conexões com campos de saber longínquos e de preferência pouco conhecidos, por exemplo, de campos lexicais desconhecidos para um aprendiz brasileiro como "neve" em língua inuíte, "aurora polar" em norueguês, etc.

Figura 4 - $4^{\circ}$ e $5^{\circ}$ anos

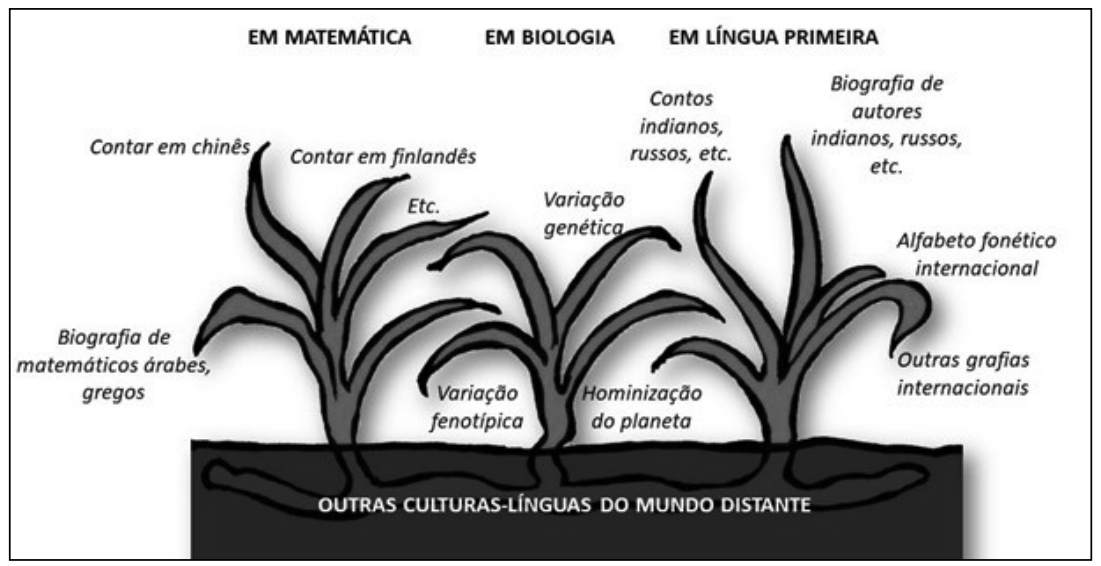

Fonte: Elaborada pelo autor 


\section{Parceiros de uma educação para a diversidade das culturas- línguas na escola}

As famílias: Esta abordagem da diversidade fundada na alteridade pode entrar em conflito direto com valores familiares contrários seja por orientação política, seja por obediência religiosa. Mesmo que a alteridade seja um valor em comum, a sua abordagem nestas duas situações familiares é provavelmente partidária na primeira e dogmática na segunda. Ora, um projeto escolar de educação para a diversidade visa, pelo contrário, a uma abordagem neutra e laica para expor a variedade sem julgar ou convencer.

Porém, se a construção de uma competência alteritária depende principalmente do projeto escolar e do seu corpo docente, o seu desenvolvimento depende das famílias e dos contextos familiares. Sem o apoio cooperativo da família, a chance de manter esta competência viva além da escola é quase nula (BRUN, 2015). Todo projeto de educação para a diversidade das culturas-línguas precisa envolver constantemente as famílias, recorrendo às suas competências e mantendo-as informadas.

Corpo docente: A competência alteritária, finalidade de uma educação para a diversidade, só pode ser fruto de um lento processo de construção (e possíveis desconstruções) que depende da colaboração entre os três atores escolares: criança, família e corpo docente. Se a família e a criança se entregam normalmente à competência legítima do corpo docente, este nem sempre está preparado ou desejoso para descontruir o próprio sistema representacional discriminante sustentado, às vezes de forma inconsciente, por estereótipos transmitidos pelas gerações anteriores e observados mediante as expressões idiomáticas com forte conotação discriminante: cor da pele, advogado do diabo, a dar com pau, meia tigela, mulata, cor do pecado, ter um pé na cozinha, cabelo ruim etc. Frequentemente, o discurso docente se revela impregnado e contaminado por tendências discriminantes, fruto do imprinting cutural que é, segundo Konrad Lorenz, gerado pelo conformismo cognitivo e pela normalização, ambos descobertos dentro da família, da escola, da universidade e da atividade profissional e que visam eliminar qualquer contestação (MORIN, 2000, p. 27-28).

A dificuldade para reverter um preconceito, seja ele negativo (desvalorização do outro), seja ele positivo (valorização), provém do seu 
estatuto de cognição implícita (LORENZI-CIOLDI, 2002, p. 45, nossa tradução) que o ancora profundamente no adulto. Este preconceito precisa ser em primeiro lugar detectado e identificado no educador, para que se tenha uma chance de ser evitado no aprendiz. Assim, qualquer projeto pedagógico-didático de educação para a diversidade depende da formação prévia do próprio corpo docente parceiro.

Sem a total cooperação alteritária deste corpo docente e a sua capacidade de autoidentificar o ressurgimento no seu discurso de resquícios estereotípicos, preconceituais e às vezes discriminantes, a competência alteritária ensinada já se encontra irremediavelmente prejudicada, apesar do projeto alteritário do qual o corpo docente participa (BRUN, 2015). Segundo Dominique Groux et Louis Porcher (GROUX; PORCHER, 2003, p. 95-96, nossa tradução): "o reconhecimento da alteridade exige uma aprendizagem, um treino, um esforço, que só pode resultar de uma educação no mesmo tempo familiar e escolar de maneira convergente". A visão educativa que o corpo docente do Ensino Fundamental tem acerca das culturas-línguas parece ser ainda basicamente binária e o objetivo deste campo de saber seria fornecer de forma pragmática um instrumento de comunicação com outro locutor, em regra geral, distante.

Ora, a didática de outra cultura-língua é um campo de saber que perpassa todos os outros campos escolares de saber já que ele só existe em razão de um outro mais ou menos diferente, vivo e que se expressa de forma verbal ou não. Enclausurar as culturas-línguas na escola na disciplina Língua Estrangeira Moderna é perder totalmente o seu potencial educador global. Além deste fechamento disciplinar, o próprio pertencimento do(a) educador(a) ou da escola a um grupo com tendência etnocêntrica pode se tornar um obstáculo previsível a qualquer projeto de uma educação para a diversidade sem um consenso prévio que parece, de qualquer forma, bastante comprometido.

\section{Considerações finais}

Uma educação para a diversidade por meio das culturas-línguas não trata do ensino formal e completo de uma cultura-língua, mas do descobrimento da maior variedade para estimular a curiosidade das crianças e as suas atitudes positivas em relação às diferenças. Assim, o corpo docente não precisa ter um saber específico em outra cultura-língua, mas ele precisa apenas possuir uma competência alteritária, que vai 
contribuir na sua didática quotidiana a ensinar as conexões complexas às vezes entre homogeneidade e heterogeneidade, entre semelhanças e diferenças, entre preconceito e alteridade. $O$ corpo docente deve procurar com as famílias as competências culturais-linguísticas que faltam na sua própria formação acadêmica e pessoal. Esta participação é fundamental.

É preciso ressaltar o quanto o processo de humanização da humanidade através da alteridade é um processo lento e consciente. Não nascemos predispostos para ter empatia com o outro diferente seja numa situação de dor, seja numa situação de alegria. Precisamos ainda aprender a sermos alteritários. Esta dinâmica se espelha na evolução constante das leis acerca das discriminações para acompanhar as transformações identitárias dos grupos humanos que passam a reivindicar cada vez mais o direito de ser diferente.

A principal dificuldade societal é a internalização desta reivindicação identitária dos indivíduos pela coletividade. A própria evolução legal num curto período no Brasil mostra o quanto a coletividade está sempre atrasada em relação ao indivíduo que a compõe. Se a lei brasileira previa os crimes resultantes de preconceitos de raça ou de cor desde 1989 (BRASIL, 1989), ela precisou posteriormente (BRASIL, 1997) ser alterada para incluir novas formas discriminatórias como a etnia, a religião ou a procedência nacional. Se a incorporação legal de outras possíveis discriminações se faz necessária cada vez mais, é que de um lado há uma explosão de reivindicações identitárias individuais, e do outro lado há o reconhecimento destas reivindicações pela coletividade, mesmo que seja uma atitude aparente e ainda não assimilada. Esta mutação societal por enquanto parece lenta e aleatória, mas o sistema de educação nacional pode conseguir estimular e promover a alteridade a médio prazo para institucionalizar uma nova inteligência: a inteligência do convívio interpessoal harmonioso.

\section{Referências}

ABRIC, J.-C. et al. Pratiques sociales et représentations. PUF, 2001.

BERGER, P. ; LUCKMANN, T. La construction sociale de la réalité. Paris: Armand Colin, 2010.

BLANCHET, P. Discriminations: combattre la glottophobie.Paris: Éditions Textuel, Petite encyclopédie critique, 2016. 
BLANCHET, P. ; CHARDENET, P. Guide pour la recherche en didactique des langues et des cultures. Paris: Editions des archives contemporaines, 2011.

BRASIL. Parâmetros Curriculares Nacionais. Parâmetros curriculares nacionais: terceiro e quarto ciclos do ensino fundamental: língua portuguesa. Brasília: MEC/SEF, 1998.

BRASIL. Lei 7.716 de 5 de janeiro de 1989. Diário Oficial [da] República Federativa do Brasil, Brasília, 5 jan. 1989.

BRASIL. Lei n. 9.459, 13 mai. 1997: Define os crimes resultantes de preconceito de raça ou de cor, e acrescenta parágrafo ao art. 140 do Decreto-lei no 2.848, de 7 de dezembro de 1940. Diário Oficial [da] República Federativa do Brasil. Brasília, DF, mai. 1997.

$B R U N$, E. Sur l'évolution altéritaire-ethnocentriste en classe de cycle $\mathbf{2}$ dans le cadre d'un projet d'Éveil aux langues-cultures du monde: une analyse comparative longitudinale à travers l'expression orale. Tese (Doutorado em Ciências da Linguagem), Aix-en-Provence, 2015, Laboratoire parole et Langage, Université Aix-Marseille.

BRUN, E.; BRUN, M. Educação para a diversidade das línguas-culturas do mundo na educação infantil: desenvolvendo a competência transcultural. Fólio Revista de Letras, Vitória da Conquista, v.8, n.2, 2016.

CANDELIER, M. Le CARAP : un cadre de référence pour les approches plurielles des langues et des cultures: compétences et ressources. Strasbourg : Editions du Conseil de l'Europe, 2012.

CHINI, D.; GOUTÉRAUX, P. Intégration de l'altérité dans l'apprentissage des langues. Formes didactiques et procédures psycholinguistiques. Paris : L'Harmattan, 2011.

CLERC, S. Vers une didactique de la pluralité sociolinguistique. Cheminement de la didactique du français langue étrangère à la sociodidactique des langues. Mémoire d'Habilitation à Diriger des Recherches, Université de Provence, 2011.

DIXON, T. La science du cerveau et la religion de l'Humanité : Auguste Comte et l'altruisme dans l'Angleterre victorienne, Revue d'histoire des sciences, n. 2, Tome 65, p. 287-316, 2012. 
FRANÇA, Repères \& référencesstatistique : enseignements, formation, recherche. Paris: Ministère de l'Éducation Nationale, Ministère de l'enseignement supérieur, de la recherche et de l'innovation, 2017.

GROUX, D. ; PORCHER, L. L'altérité, Paris : L'Harmattan, 2003.

LAMARRE, M. L'éducation cosmopolitique: apprendre le propre, apprendre l'étranger, Le Télémaque, Caen: Presses universitaires de Caen, n. 41, p.31-46, 2012.

LORENZI-CIOLDI, F. Les représentations des groupes dominants et dominés. Collections et agrégats. Grenoble : PUG, 2002.

MORIN, E. Science avec conscience. Paris : Fayard, 1982.

MORIN, E. La méthode 4. Les idées: Leur habitat, leur vie, leurs mœurs, leur organisation, Paris : Éditions du Seuil, 1991.

MORIN, E. Terre-Patrie. Paris, Seuil, 1993.

MORIN, E. Les 7 savoirs nécessaires à l'éducation du futur. Paris : Seuil, 2000.

MORIN, E. La méthode 6.Éthique. Paris: Éditions du Seuil, 2004.

MORIN, E. Culture et barbarie européennes. Montrouge : Bayard, 2009.

PEREIRA DE SÁ, C. Núcleo central das representações sociais. Rio de Janeiro: Vozes, 1996.

PREISSING, C. WAGNER, P. (Org.) Les tout-petits ont-ils des préjugés? Éducation interculturelle et antidiscriminatoire dans les lieux d'accueil. Ramonville Saint-Agne : ERES, 2006.

ROUSSEAU, J.-J. Discours sur l'origine et les fondements de l'inégalité parmi les hommes. Paris : Librairie de la Bibliothèque Nationale, 17551894.

VILLENAVE, B. La discrimination positive: une présentation.Vie sociale, Paris, ERES, n.3, p. 39-48, 2006.

VINSONNEAU, G. Culture et comportement. Paris : Armand Colin, 2000.

Recebido: Abril/2019

Aceito: Dezembro/2019 